\title{
Trabalho integrado para melhoria de indicadores Materno-Infantil do Distrito Sanitário Norte em Belo Horizonte: PET SAÚDE/Gradua SUS
}

Juliana Cristina Menezes, Marcus Vinícius da Silva Costa, Kátia Ferreira Costa Campos, Keli Bahia Felissíssimo Zocratto, Flávia Amorim

\section{Resumo}

Introdução: Para enfrentar os desafios inerentes à gestão do sistema público saúde, em um ambiente político, econômico e social específico, é necessário o desenvolvimento de competências e habilidades de gestão capazes de integrar diferentes saberes e tecnologias. Considera-se que a integração ensino-serviço é uma estratégia que pode proporcionar o desenvolvimento do aluno, e nesse sentido, o Programa de Educação pelo Trabalho em Saúde (PET Saúde), tem proporcionado aprendizado aos profissionais de saúde e acadêmicos, na forma de vivências e estágios, que contemplam as necessidades do SUS de educação pelo trabalho. O Programa se desenvolve por meio de integração interdisciplinar, parceria da Secretaria Municipal de Saúde (SMSA) de Belo Horizonte e a Universidade Federal de Minas Gerais (UFMG). As atividades de aprendizagem são coordenadas por tutores (professores universitários) que, em articulação com os preceptores (profissionais de áreas da rede municipal de saúde) e alunos de graduação, constituem a equipe de atuação no PET Saúde. Objetivo: Relatar a experiência dos processos integração ensino/serviço/comunidade a partir de um olhar específico da gestão sobre os indicadores Materno Infantil nos serviços da APS, na Região Norte de Belo Horizonte. Métodos: Trata-se de um relato de experiência da proposta desenvolvida pelo PETGraduaSUS do Curso de Gestão de Serviços de Saúde /UFMG desde maio de 2016 com previsão de término em fevereiro de 2018. As ações estabelecidas junto ao serviço estiveram vinculadas ao ciclo de vida Materno-Infantil do município de Belo Horizonte, e foram delineadas a partir de diagnósticos situacionais com posterior desenvolvimento de projetos de intervenção em cada campo estabelecido. Resultados: O local de atuação do PET GraduaSUS identificado pela SMSA no Distrito Sanitário Norte foi o Núcleo de Educação Permanente (NEP-Norte), constituído em março de 2012 com a proposta de organizar, estruturar e operacionalizar o Plano de Educação Permanente Distrital (PLANEP), em consonância com as diretrizes da Secretaria Municipal de Saúde (SMSA) e Centro de Ensino em Saúde - CES. Os alunos do PET Saúde acompanharam as atividades desenvolvidas pelo NEP, em todas as etapas que possuem foco na reestruturação da assistência materno infantil, em especial, as ações de educação continuada que foram desenvolvidas com esta finalidade. Para tanto, os discentes conheceram os C.S. e percorreram os pontos da rede de atenção e de informação envolvidos com a atenção materno infantil, compreendendo o processo de problematização e revisão das práticas na busca de soluções construídas coletivamente. Identificando situações sensíveis aos processos educacionais de qualificação da assistência, a fim de contribuir com os processos de discussão e ações necessárias ao alcance dos objetivos traçados no processo. A primeira fase constituiu-se na Criação da Comissão Gerencial que foi formada por gerentes distritais, referências técnicas, representantes do NEP, alunos do PET, GEAS - Gerência de Assistência, Centro de Educação em Saúde- CES, referência do Hospital Sofia Feldman (maternidade referência do Distrito Norte). Foram feitas reuniões em que discutiu-se a situação dos indicadores da Regional Norte e quais seriam as intervenções para que melhores resultados fossem alcançados. Dentre as ações constituintes do projeto estavam a sensibilização com os gerentes dos C.S. da Norte, reuniões de "Pólos" (divisão de unidades com territórios próximos) com grupos menores de gerentes para estudo detalhado dos indicadores a partir da realidade loco regional, momento de apresentação e 
ISSN 2179-6750

discussão desses indicadores com os profissionais das unidades e desenvolvimento de processos educacionais com as categorias profissionais que influenciam direta ou indiretamente no atendimento às gestantes. Já na segunda fase, a Sensibilização dos Gerentes das Unidades de Saúde foram feitas reuniões, com os Gestores locais, com o intuito de abordar o tema e iniciar as discussões em relação às mudanças necessárias para a melhoria dos indicadores materno-infantis, reduzindo a postura reativa dos gestores frente aos apontamentos sobre o cuidado perinatal no Distrito Sanitário Norte. A terceira fase ocorreu com as Reuniões de Pólo com aplicação de questionários com os gerentes, sobre avaliação dos critérios de atendimento às gestantes nas unidades de saúde. Diante das respostas enviadas pelas unidades, foi possível identificar e discutir os principais problemas encontrados em cada equipe de saúde. Como proposta de ação os gerentes fizeram discussão com todos os profissionais de sua unidade e identificaram estratégias de enfrentamento dos problemas de cada território. Na quarta fase, realizou-se a capacitação com médicos, enfermeiros e outros profissionais da Atenção Básica nas Equipes de Saúde da Família das unidades da Regional Norte, com o objetivo de refletir a prática, sensibilizar os profissionais e problematizar sobre a realidade da unidade, as mudanças necessárias no processo de trabalho e condutas durante a assistência à gestante. Foram discutidos alguns tópicos durante os quatro módulos da Capacitação: organização do pré natal, primeira consulta pré natal, estilo de vida e comportamento, queixas comuns na gestação, pesquisa de infecções, triagem para anomalias fetais, problemas hematológicos, triagem e diagnóstico de complicações clínicas e obstétricas, final de gravidez, plano de parto e aleitamento materno. Anteriormente ao início do curso, os profissionais respondem um Pré-teste que contempla questões pertinentes às discussões do módulo. E após o curso, os mesmos responderam a um Pós- Teste que avalia os avanços alcançados. Os profissionais foram divididos em grupos pequenos e um facilitador direcionou as discussões, apontando as questões a serem refletidas por cada participante, através de um caso com uma situação real do cotidiano destes profissionais no atendimento a uma gestante. Na quinta e última fase, foram feitos acompanhamento dos Planos de Ação Materno-Infantil nas unidades básicas de saúde. Para avaliação do Projeto, foi realizada uma seleção aleatória de duas unidades para acompanhamento dos planos de ação, através do instrumento $5 \mathrm{~W} 2 \mathrm{H}$, utilizado nas disciplinas Estratégias de Planejamento e Planejamento, Programação e Avaliação em Saúde, no Curso de Gestão de Serviços de Saúde. Os gestores e profissionais de saúde das duas unidades também responderão a um questionário elaborado que identificou as principais questões que envolvem a Assistência à Mulher. Foi realizado também uma pesquisa de satisfação com as usuárias gestantes e puérperas, que apontará os avanços, mudanças e questões que ainda merecem ser observadas no atendimento. Esse resultado norteará revisão de disciplinas no curso. Uma reavaliação trimestral dos planos de ação e indicadores das unidades escolhidas será necessário para o acompanhamento da evolução de cada uma delas. Nesse sentido, propõe-se nas unidades que acolhem o estágio obrigatório, dar continuidade no projeto. Conclusões: Prospecta-se com o projeto proposto contribuir para a melhoria da atenção a saúde da criança e gestante, bem como gerar produtos que possam ser divulgados de modo a influenciar outras unidades da rede de atenção municipal. Espera-se também, acumular experiência capaz de proporcionar o estabelecimento de critérios para adequar a proposta curricular do curso de Curso de Gestão de Serviços de Saúde baseada na experiência vivenciada no PET GraduaSUS.

Descritores: Educação, Educação em saúde, Políticas públicas, Gestão de serviços de saúde 